\title{
Implementation and impact of Industry 4.0 and Quality 4.0 in the banking sector
}

\author{
Celina Pogăciaș ${ }^{1}$, and Raluca Dovleac ${ }^{2, *}$ \\ ${ }^{1}$ Doctoral School, University of Petroșani, Romania \\ ${ }^{2}$ Management and Industrial Engineering Department, University of Petrosani, Romania
}

\begin{abstract}
The digitalization of banking services refers not only to the application of new technologies, but also involves a completely different approach and way of thinking for all actors involved. Given the dominance of the technological environment and unprecedented customer expectations, banks in Romania have concluded that the practices of quality management can be implemented for banking activities, inspired by the actions of international banks that have entered the national market. Knowing and anticipating customer needs and expectations as they evolve, by focusing on achieving and maintaining a maximum degree of satisfaction to retain customers is a primary objective for all banks. It is strategically relevant that the impact of Industry 4.0 on the transformation of the banking sector does not jeopardize security, which fuels the need for a balance between competition, innovation, security and customer satisfaction. In addition to the accelerated digitalization processes in the banking sector, the human factor will continue to play a key role in the future, as the focus will remain on the bank's customer, security and trust. The aim of the paper is to explore the possibilities of implementing Quality 4.0 and Industry 4.0 in banking systems and their impact by studying the literature.
\end{abstract}

\section{Introduction}

In the last thirty years, civilization has gone through three industrial revolutions, and the fourth industrial revolution also called Industry 4.0. is in progress. Each of these industrial revolutions has been characterized by technological innovations that have had a strong impact on the development of all mankind. Characteristic for Industry 4.0 is that it affects business models, while developing digital and other technologies, but it also affects the entire lifestyle in the world. After the process of globalization, which led to the expansion of business, a new era began, which can be called the era of digital transformation. The basic feature of the digital age is that it takes on new dimensions and new shapes, from one day to the next.

\footnotetext{
* Corresponding author: raluca.dovleac@yahoo.com
} 
Industry 4.0., i.e., the digitalization of industry is a topic that people are trying to find answers to, how economies can be more competitive in global markets.

Klaus Schwab, founder and president of the Davos Forum, addresses this issue in his book "The Fourth Industrial Revolution", in which he analyses the effects of development that are different from everything that happened during the other three industries [1]. The use of

digitalization in the industry of modern countries could in the next period lead to the loss of a significant number of jobs which would increase productivity and efficiency and ensure competitiveness in the global market. Its main focus is smart factories, which effectively integrate customers and business partners into a single process, and the new approach to Industry 4.0 is the network of smart digital devices with products, tools, robots and people.

The first use of the term "digitization" appeared in a 1971 essay first published in the North American Review in which Robert Wachal discusses the social implications of "the digitization of society." Since then, all published subjects on digitization have become a massive literature.

Specialists have argued that using a single interconnected system - the digital communication system connects almost all areas of social life. This communication system is entirely characterized by "new media", often defined simply as environments capable of receiving and manipulating digital signals. There are a number of ways to analyse how digitization is shaping the contemporary world, for example, the rise of globalization, which has facilitated the expansion of the economy beyond national borders through digitization [2].

The digitalization and globalization of the economy subsequently eroded national sovereignty with different conceptions of materiality by facilitating new circuits of culture, capital, goods and people. In finance, many experts have shown how the digital media is now the central part of global capital flows. Specialists argued that digital media and computers presented a new history at one point, just as mechanization facilitated the Industrial Revolution.

Previous industrial revolutions, in addition to technological changes, have produced changes throughout society and in the economy. The fourth industrial revolution brought fundamental and essential changes and led to a completely new economy - the digital economy [3]. The digital economy is an economy based on digital technologies, primarily through the use of information technology in all areas.

The digital economy is considered a post-industrial, global economy, based on internet transactions and advanced technology, as a global network of economic activities based on information communication technology, as an economy based on digital technology is an information-based economy, knowledge, ideas and innovations. It is estimated that the digital economy is growing seven times faster than other economies and that in developed countries it produces $10 \%$ of gross domestic product, which means that the digital economy is constantly growing and the traditional economy will be moving more and more. to the digital form. According to research conducted by the European Banking Federation [4], it expects a digital single market that stimulates the development of companies and serves the well-being of all customers, additional growth and continued employment.

Many countries have made great strides in terms of technology and innovation, however there are countries that are not yet making any progress in developing innovative technology and solutions. In principle, these are countries that face problems such as: low standard of living, underdeveloped infrastructure, poverty and other problems.

The first appearances of the digitalization of the economy were internet business, ecommerce, banking and other services offered daily. The role of banks in this 
transformation is that they contribute to economic growth and development in the overall financial market, banks are not just innovative partners investing in financial technologies.

\section{The digital transformation of the banking sector, Quality 4.0 and Industry 4.0}

In recent years, banking institutions have been subject to intense competition due to globalization, technological advances and high customer expectations. The process of bank digitization has become an integral part of strategic plans and decisions for most banks. The reasons for this are that there has been accelerated progress in digital technologies, which has inevitably led to increased competition in financial services. One mechanism used by banks to gain competitive advantage is quality management.

Of course, the process of bank digitization brings new elements and possibilities for the expansion of new banking services and, in line with these, new opportunities for increasing business performance, the bank's profitability. In order to improve business results, one of the basic opportunities is reflected in the technological possibility for a better interaction with the bank's customers, as well as a more detailed and precise perspective on their needs, habits and possibilities. Applying these strategies and using modern technologies will ensure a much more efficient work of employees and establish much more productive relationships with customers.

The banks of the future will certainly be much more efficient with technologically equipped bank branches, and the services will be provided by appropriate self-service machines and computers that will focus on customers, which is the bank's main objective. What banks need to implement in the future through the process of digital transformation, are adapting services and ways of service with new ways of doing business, introducing services based on personal experience, and applying the concept of ethical banking.

The main change regarding the digital bank is in the relationship between the bank and the customers. Currently, the bank-customer interaction is activated through tablets and computers where all banking services can be performed, which can also serve as billboards at the same time. Another feature of the digital bank is innovation, i.e., a continuous process of innovation that, in addition to services, offers other activities, represented by the free use of the Internet, the presentation of local exhibitions, cooperation with insurance companies, etc. The digital bank of the future must provide its customers with an attractive and modern bank, an environment based on interactions and innovation that can provide customers with proactive and fast access to the information they need [5]. In addition, the digital bank will use new methods of communication, personal access, easier access to information and services and attractive and interactive branches. Banks that adhere to these principles will have a comparative advantage and greater customer satisfaction, organic business growth and recognition in the banking market. Even if the future of banking is in digital technologies, the customer and the banking relationship will continue to be the focus.

One of the most frequently used topics lately in Industry 4.0. it is the notion of artificial intelligence. In addition to the countless skills, improved user manuals and the provision of fast, error-free information, artificial intelligence can also be used to automate bank processes. Even if the digitization process is moving in the direction in which everything that can be digitized will be digitized, we must not neglect the fact that the key element is trust that cannot be digitized. Some banks have already created a "Chat Banking" platform based on artificial information, through which customers communicate with the bank through Facebook and Viber applications. "Chatbots" are the first use of artificial intelligence in the banking sector, through which banks respond quickly and efficiently to 
customer questions about products and services. Artificial intelligence will certainly be very important both for customer service and for customer consultation.

"Cognitive computing", which is a mixture of robotics, artificial intelligence and involves working with a large amount of data, is widely used today, being prepared a platform for the use of cognitive automation, which is more advanced than process robotics and can work with unstructured data. Although artificial intelligence brings additional innovation, speed and agility to financial operations, its purpose is for applications to have positive implications for the bank and not to affect the bank's reputation in the market.

One of the trends in bank digitalization is the emergence of blockchain technologies being determined by the emergence of cryptocurrencies. The emergence of cryptocurrencies, i.e., digital money, is an inevitable consequence of the Industry 4.0 revolution. Many cryptocurrencies have appeared in the market, but some of them have gained popularity and full assertion. One of the most popular cryptocurrencies is Bitcoin. The basic feature of this virtual money is that it works completely independent of the monetary authorities and the amount of traditional money in circulation.

Some banks have become involved and joined specialized companies engaged in these businesses, jointly developing platforms for digital trade finance based on blockchain technology. In addition to banks, other companies and specialized institutions can afford to have simpler financing and trading processes, with the advantage that they can negotiate orders, the terms of trade agreements and access to financial services offered on the platform with complete security and trust. Many banks have already begun to introduce blockchain technology that will greatly change banking services, as it allows fast, secure and cheap transfer without intermediaries.

In the future, banks will have to change their business models and adapt them either to accelerated market changes or to form an alliance with large technology companies, as well as with smaller companies that have complementary solutions. Banks will need to act proactively towards regulators and reduce their operating costs so that they can compete in both the banking and financial markets. All future changes, from an organizational point of view, will be based on the technologies and the capacity of banks to quickly overcome the new methods of processing constantly increasing amounts of data. From this point of view, most banks will become partners with FinTech companies to have joint investments in technology projects.

In parallel with the digitization process, it is necessary to adequately regulate the financial framework in order to eliminate or mitigate systematic risks. In the digital economy, customers and their data must be protected, and companies dealing with similar transactions must apply the same rules to all customers, which implies the need to find an appropriate balance between competition, innovation, security and customer protection. From a strategic point of view, it is important that the impact of Industry 4.0 on the transformation of the banking sector does not jeopardize security to the detriment of competition and innovation. Industry 4.0 has a major influence on the transformation of the banking sector, but any constraints and legal framework that could have negative consequences for this process must be taken into account.

The bank of the future will certainly be marked by an additional process of digitization of banking products and services, which means that banks must invest in new technologies, which will mean additional income but also additional investment costs in this stage of transformation.

The success of digitalization in banks will depend on other factors: educational reforms with a strong emphasis on financial literacy, human resource development models, prevention of administrative barriers and last but not least strategic support for the development of the banking sector because new technologies are unstoppable, bringing complete concepts we who force ourselves to change the way we think. The digitization of 
financial services does not only refer to the application of new technologies, but also involves a completely different approach and a completely new way of thinking for all participants.

Given the accelerated changes in recent years, we can deduce that the future of banking will certainly look different in the coming years and that artificial intelligence will replace many processes, help accelerate communication and bring superior quality to banking. However, the accelerated digitization processes, both in the banking sector and in other fields, will not eliminate the human factor but will continue to play a key role in the future, and the focus will remain on the bank's trust, security and customer.

In the era of transition to technologies and principles of Industry 4.0., despite the confirmation of the importance of using innovative methods of quality management and digital technologies, it was concluded that this process mainly involves the transformation of managerial thinking itself. All transformation processes focus on human beings as a basic element of production and consumption systems.

The transition to Quality 4.0 requires a new understanding of the relationships and responsibilities of stakeholders by changing the basic principles underlying decisionmaking in companies and not just the implementation of Industry 4.0 technologies to improve quality. Due to the fact that there has been accelerated progress in digital technologies, which has inevitably led to increased competition in financial services, the process of bank digitization in recent years has become an integral part of strategic plans and decisions for most banks.

Quality 4.0 is based on bridging the gap between consumer requirements and product properties, which arises due to the need to adapt mass products to the individual needs of a person or organization. The use of innovative methods of quality management should also be accompanied by a radical transformation of the paradigm and its principles on business or organization. Since the 1990s, new approaches to management have emerged: talent management, value-based management and sustainable development management. Because they are still disintegrated, it makes it difficult to form a new management paradigm that meets the challenges of the fourth industrial revolution. These challenges create premises for rethinking the principles of quality management. The paper summarizes the contributions of Industry 4.0 to the implementation of quality management principles, such as improving responsiveness, high coordination between all levels of the organization, efficient evaluation of results, dynamic active interaction with market needs, reconfiguration snapshots of production processes, dashboards with analytical information, etc.

\section{Drawing the path to Banking 4.0 through Quality Management}

The digitalization of the banking sector involves multiple aspects among which: the selection of the customer segments involved and the type of the relevant products and/or services that can be subject to digitalization, understanding the type and amount of data required for both the transition to a digital environment as well as the maintenance and operativity within the environment. Like so, multiple enablers are required ranging from the requirements of the bank customers and stakeholders, to the requirements of the society manifested through the increasingly competitive markets, globalization and the emergence of technological products and solutions.

In the paper, the authors propose a roadmap to digitalization in the banking sector, in order to highlight the important aspects that should be taken into account as well as to suggest possible actions and activities to be undertaken in order to achieve the goals established by banks looking to make the transition to Banking 4.0 


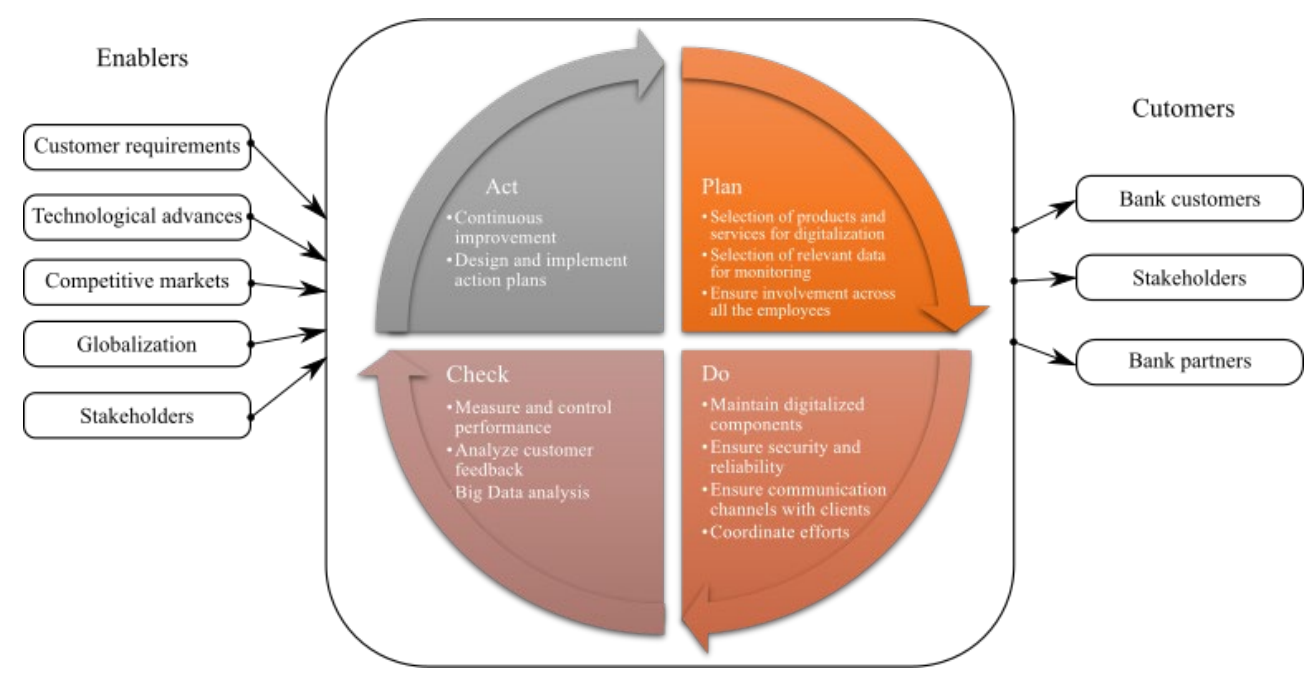

Fig. 1 Roadmap to digitalisation in the Banking sector

Therefore, the roadmap is based on three major parts: The Enablers - highlighting all the possible factors that are related to the implementation of digitalization practices; The customers - describing the types of customers that could benefit from the digitalization of bank products, services and/or operations; The action plan, describing activities involved both in the planning phase, as well as those involved in the implementation, maintenance, control and improvement of operations for Banking 4.0 in the form of the Plan Do Check Act (PDCA) cycle. The PDCA cycle has been used in order to provide a graphical and easy to follow depiction of activities involved in each stage.

Like so, in the "Plan" phase activities that relate to the understanding of the bank's requirements and capabilities take place, with the role of establishing the tools, methods and techniques that can aid the implementation and transition to Banking 4.0 according to the particularities of the bank and its customers.

During the duration of the next phase - "Do" two main activities are required: 1. Maintaining and updating the components used by the bank, along with the security and reliability of the activities conducted 2 . Coordinating team efforts in order to ensure the involvement across the entire personnel as well as maintaining and developing the communication channels with the current clients and the potential ones.

In the "Check" phase, the organization should be concerned with measuring performance by analysing the available data, coming both from the customers, in the form of customer feedback, as well as data coming from the system in the form of Big Data.

In the last phase - the "Act" phase, efforts should be concerned with ensuring that continuous improvement is an active part of the system. This can be done by designing and implementing action plans based on the results gathered from the Check phase as well as making changes in the organizational culture and practice if necessary.

\section{On the digitalization path in the Romanian banking sector - The level of usage of digital banking in the largest banks in Romania}

In Romania, it was observed that the marketing efforts made to promote the banking internet were continuous and aggressive on various media channels as well as within banks, which determined that between $29 \%$ and $71.5 \%$ of the customers of the largest banks to 
become digital customers. The most digitized portfolios are those from ING Bank, BCR and Banca Transilvania. In order to observe how much are used the digital internet banking and mobile banking solutions provided by the largest banks in our country, we analysed how much of the total number of customers are active users of remote banking services. The five banks analysed Banca Transilvania, BCR, BRD, ING Bank and Raiffeisen Bank together have just over 6 million digital customers, who frequently use internet banking and mobile banking services.

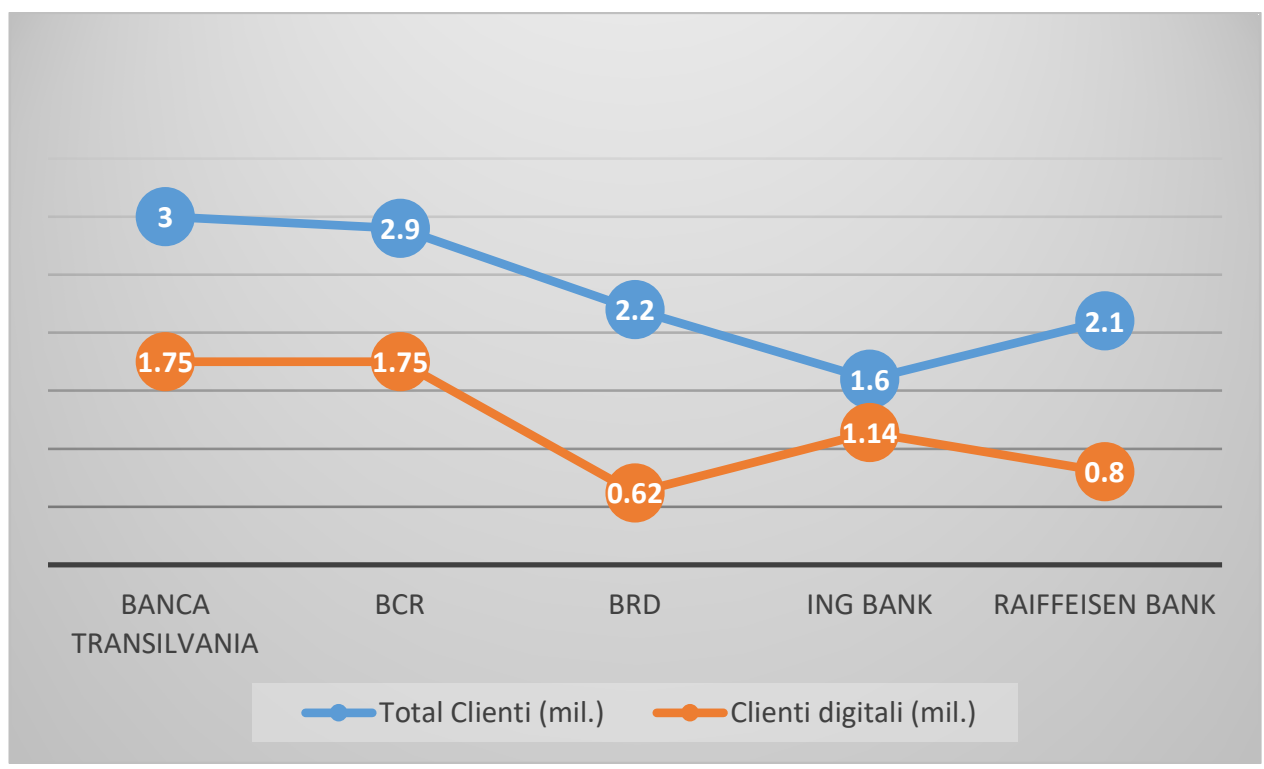

Fig. 2 Comparative analysis of digital customers of major Romanian banks

ING Bank, the Dutch-owned bank, ranks first among local banks in terms of the proportion of digital customers in the total portfolio. Of the 1.6 million customers [6], about 1.14 million actively use Home'Bank, resulting in a percentage of approximately $71.5 \%$. ING Bank is the first bank in our country and the only one that no longer uses any classic counter for cash transactions, the cashiers that cashed and released cash being abolished in 2018. Even if last year, for the first time in the history of ING Bank, card payments exceeded cash withdrawals, comparing the activity of the bank in Bucharest with that of digital banks in developed countries, where the adoption of new technologies far exceeds $90 \%$, we can say that ING Bank still has a lot of work to do until it reaches the title digital banking, given the many and repeated problems that ING Bank customers have faced in recent years regarding the proper functioning of digital cards and services.

With the launch of the George digital platform, 2 years ago, BCR managed to grow aggressively in terms of digitalization. The bank has already reached over 1 million active users for George. BCR has a total of 1.75 million Internet Banking and Mobile Banking users [7], which means that $60 \%$ of the total customer portfolio $(2.9$ million $)$ is digital. The bank has taken a series of measures aimed at transferring as many customers as possible to the adoption of new technologies. Thus, it was possible to transform some branches into real banking hubs, today almost half of the BCR branches are cashless. In the BCR Cashless strategy it is not - an agency without staff, but an agency in which the employees are $100 \%$ dedicated to the counselling activity, the classic operations being carried out electronically, without cashiers.

Out of the desire to build a new trend on the banking market, starting with October 2020, a new way of operating has been implemented throughout the territorial network, 
through which customers have access to branches exclusively based on telephone or online scheduling. The experience of the first days of the program showed that almost $50 \%$ of customers who called for programming did not need to go to the branch, their problem can be solved by using digitization. Through the new practices adopted, BCR's approach tends to be in fact a concept of digital education, teaching customers to go to branches only when they need counselling.

The percentage of digital clients at Banca Transilvania in the total portfolio is $58.5 \%$. The largest bank in Romania by asset level has 1.75 million digital unique customers who have at least one of the BT applications [8], especially BT Pay, BT24 Internet Banking and Mobile Banking. Banca Transilvania has registered a considerable jump in the number of customers in recent years, amid the organic growth but also the takeover of Volksbank and Bancpost. Practically, in the last 5 years, Banca Transilvania has managed to complete its portfolio with about 800,000 customers, reaching today approximately 3 million consumers, compared to 2.2 million in 2016. NEO is an essential pillar in Banca Transilvania's plan to build the best online experience for its own customers.

Raiffeisen Bank aims to continue to offer the best banking experience, in the best financial conditions for customers, which is why in 2019, Raiffeisen Bank continued the digital transformation process, launching new Mobile and Internet Banking applications: the new Smart Mobile, respectively the new Raiffeisen Online. With an intuitive and friendly design, the new apps display all your account information in one screen, provide a streamlined payment flow and better card control. Another novelty was Raiffeisen SmartToken, the smartphone application that allows customers to $\log 100 \%$ online in new applications. They are developed in-house by the Raiffeisen Bank IT team and allow faster introduction of functionalities.

The Bank's efforts focus on financial education since the account was opened and on migration to alternative channels. These applications aim to improve the user experience, ensure the availability of services anywhere and anytime, offering even the lowest costs for banking operations. In 2019, the number of digital customers approached 700,000 [9], and over 450,000 already use the new platforms. By the end of 2019, one in two digital customers was making at least one transaction in online and mobile banking applications.

The share of customers who currently use digital channels increased from 55\% in 2018 to $63 \%$ at the end of 2019 , and the volume of electronic transactions reached $94 \%$ of the total.

A very popular option for customers is Smart Hour, in which Raiffeisen Bank customers can exchange rates at the BNR exchange rate. In the new Raiffeisen Bank applications, for one hour, between 10:00 and 11:00, from Monday to Friday, Raiffeisen Bank customers can exchange euros or Swiss francs in lei or vice versa, in their own accounts, at the NBR exchange rate on the day of the performance. exchange.

Desiring to provide a streamlined customer experience, Raiffesen Bank launched digital phone and smartwatch payments in 2019, reaching over 100,000 customers using RaiPay (Android), Apple Pay (iOS) and Garmin Pay (Garmin watches).

RaiPay is the phone payment application for Android operating systems, with the help of which customers can pay contactless, fast and secure, bringing the smartphone closer to POS. Designed as a digital wallet, RaiPay allows users to enrol multiple Raiffeisen Bank cards, either by individuals or companies.

Also starting in 2019, Raiffeisen Bank cards can be enrolled in Apple Pay, a payment application with iPhone or Apple Watch. Authorization of payments is done by Face ID (with face recognition) or with a simple touch, by Touch ID (fingerprint recognition), or with the password of the device.

The end of the year came with the launch of Garmin Pay, the payment application with Garmin watches, used mainly by sports enthusiasts. The devices allow both the 
measurement of sports performance and the making of payments without the need for physical cards.

In line with the Raiffeisen Bank brand - "Banking as it should be", based on a partnership with a top supplier, the bank has implemented, through a pilot program, the operational platform Customer Experience PULS, able to provide a centralized portfolio perspective of customers in real time. The platform provides a starting point for improving the quality of products and services offered, based on customer feedback.

The degree of equipment for BRD individual customers continued to increase due to the intensification of trade relations. The use of digital channels continued to intensify, as reflected in the growing number of single active users of internet and mobile banking services to almost 600 at the end 2019 [10], increasing by $46 \%$ in the last two years. At the same time, the volume of transactions through electronic channels increased rapidly, by $24 \%$ compared to 2018 . The degree of digital penetration also accelerated in the segments of SMEs and large companies, over $97 \%$ of transactions being made through electronic channels, collecting over 1 million payments per month. Focusing on customers and their needs, in a world in full technological change, BRD launched, in November 2020, YOU, its new digital banking application, with an intuitive and friendly design, for the safe implementation of banking operations. day by day. With a constant focus on innovation and improving the customer experience, BRD has launched several digital solutions for its customers: a new mobile application for corporations, which offers real-time access to accounts in full security and mobility, an end-to-end digital solution. fully integrated to-end for factoring and a digital trade finance platform dedicated to the fast and secure management of guarantees, letters of credit and receipts.

As expected, the percentages differ greatly, depending on how determined the credit institutions were in adopting the digitization and, at the same time, depending on the measures implemented such as closing the counters, additional taxation of cash transactions at cashiers to direct own customers to the online environment.

\section{Conclusions}

New technologies are constantly appearing, bringing with them completely new concepts that require us to change the way we think. The digitization of financial services does not only refer to the application of new technologies, but also involves a completely different approach and a completely new concept of thinking of all participants. Given the accelerated changes in recent years, we can say that the future of banking will certainly look different in the coming years, artificial intelligence will replace many processes, will help accelerate communication and better-quality banking.

Organizationally, all future changes will be based on the technologies and capabilities of banks to quickly overcome the new methods of processing ever-increasing amounts of data. Many banks become partners with FinTech companies and have joint investments in technology projects. In parallel with the digitization process, it is necessary to adequately regulate the financial framework in order to eliminate or mitigate risks.

The security environment brings new challenges, threats, but also development opportunities for a collective solution to the problems facing the IT industry. The demands of different users of banking services and new customers are essentially reduced to the requirements of different generations of users. Regardless of the belief that the largest users of digital services are the younger generation, which grew up in the digital age, studies have shown that older generations have quickly adopted and mastered digital methods of communication and digital business.

Analyzing current trends in the development of digitalization of banking services, it is clear that banks will need to change their business models and adapt them to market 
requirements. From an organizational point of view, all future changes will be based on the ability of banks to quickly master new methods of processing increasing amounts of data. In the digital economy, it is necessary to protect both customers and their data, to harmonize companies that run similar businesses and to apply the same rules to all market participants. This implies that an appropriate balance needs to be struck between competition, innovation, security and customer protection. It is important that Industry 4.0's transformations in the banking sector do not jeopardize security to the detriment of competition and innovation.

However, we can say that, despite the accelerated digitization processes, both in banking and in other fields, the human factor will continue to play a key role in the future, and the focus will continue to be the trust, security and customer of the bank.

\section{References}

1. K. Schwab "The Global Competitiveness Reports. Chapter 3: Benchmarking Competitiveness in the Fourth Industrial Revolution" Geneva World Economic forum, (2018). [Online]. Available: http://reports.weforum.org/global-competitiveness-report2018/chapter-3-benchmarking-competitiveness- in-the-fourth-industrial-revolutionintroducing-the -global-competitiveness-index-4-0/

2. S. Sassen, "Globalization and its discontents: Essays on the new mobility of people and money", (1998), New Press

3. V. Lazović, T. Đuričković, "Digitalna ekonomija. CIP - Katalogizacija u publikaciji", Nacionalna biblioteka Crne Gore, Cetinje, (2018)

4. World economic Forum, Readiness for the Future of Production Report, (2018)

5. The Banker, Branches of the future - changing for the digital age, (2018)

6. https://www.ing.ro

7. https://www.bcr.ro

8. https://www.bancatransilvania.ro

9. https://www.raiffeisen.ro

10. https://www.brd.ro 